\title{
Nutritional Status in Intensive Care Unit: A Meta-Analysis and Systematic Review
}

\author{
Mohammed Ibrahim Mohialdeen Gubari 1, Mohammad Javad Hosseinzadeh-Attar ${ }^{1,2}$, Mostafa Hosseini 3 , \\ Fadhil Ahmed Mohialdeen ${ }^{4}$, Haval Othman ${ }^{5}$, Khalid Anwar Hama-ghareeb ${ }^{6}$, Abdolreza Norouzy ${ }^{1} \mathbb{}$
}

\footnotetext{
Department of Clinical Nutrition, School of Nutritional Sciences and Dietetic, Tehran University of Medical Sciences, Tehran, Iran ${ }^{2}$ Centre of Research Excellence in Translating, Nutritional Science to Good Health, The University of Adelaide, Adelaide, Australia ${ }^{3}$ Department of Epidemiology and Biostatistics, School of Public Health, Tehran University of Medical Sciences, Tehran, Iran

${ }^{4}$ Community Health Department, Technical College of Health, Sulaimani Polytechnic University, Sulaimani, Iraq

${ }^{5}$ General Shar Teaching Hospital, ICU Unit, Sulaimani, Iraq

${ }^{6}$ General Director of Health, Research Center Department, Sulaimani, Iraq
}

\begin{abstract}
It is important to consider the nutritional status of patients in the intensive care unit (ICU) since it is a key element in the ability to overcome and survive critical illnesses and clinical outcomes. The aim of the present study was to provide a meta-analysis and systematic overview in determining the nutritional status of patients in ICU by examining other studies. All studies published during 2015-2019 on nutritional status in ICU were retrieved from Medline (via PubMed), Embase, Scopus, and Web of Science databases. Finally, 23 articles were included in the meta-analysis. Results obtained from these studies showed that the nutritional status of patients in ICU was inappropriate (the pooled proportion of malnutrition was 0.51 in the type of study stratified), in which many patients in this unit had different degrees of malnutrition (moderate-mild malnourished and severe malnutrition is 0.46 and $20 \%$, respectively). According to the results of this study, the nutritional status of patients in ICU was unsatisfactory; hence, it is necessary to consider the nutritional status along with other therapeutic measures at the beginning of the patient's admission.

[GMJ.2020;9:e1678] DOI:10.31661/gmi.v9i0.1678
\end{abstract}

Keywords: Nutritional Status; Intensive Care Unit; Systematic Review; Meta-Analysis

\section{Introduction}

$\mathrm{T}$ he intensive care unit (ICU) is a specialized ward at the hospital, in which patients with severe problems are admitted and undergo constant care and close supervision [1]. Most patients in ICU are unable to maintain a healthy diet due to their life-threatening and sometimes unconscious conditions [2]; therefore, paying attention to the nutritional status of patients in these units is very import-

\section{GMJ}

Copyright(C) 2020, Galen Medical Journal. This is an open-access article distributed under the terms of the Creative Commons Attribution 4.0 International License (http://creativecommons.org/licenses/by/4.0/) Email:info@gmj.ir ant and is considered as one of the main factors in these wards [3]. In ICU, the nutritional status is a key factor in the ability to overcome critical diseases and to improve clinical outcomes $[4,5]$. Nutrition and disease are closely related [6]. The reduction of nutrient intake, along with the increase in body needs and/or the use of modified nutrients, brings about the need to maintain homeostasis in ICU patients. On the other hand, these patients tend to have metabolic stress following a critical condition,

\footnotetext{
Correspondence to:

Dr. Abdolreza Norouzy, Department of Clinical Nutrition, School of Nutritional Sciences and Dietetic, Tehran University of Medical Sciences, Tehran, Iran Telephone Number: 09153145073

Email Address: arnorouzy@sina.tums.ac.ir
} 
in which they develop systemic inflammatory responses [7]. Consequently, metabolism increases, and if adequate calories and protein are not provided for a healthy metabolism, it increases catabolism, reduces fat storage, and decreases muscle mass [8]. These conditions lead to protein-energy malnutrition (PEM), which is a major problem of hypercatabolic patients with severe conditions in the ICU [6, 8]. Studies have shown that malnutrition in ICU patients is more compared to other patients $[9,10]$. In a study by Verghese et al., it was shown that all the studied patients admitted to the ICU had different levels of malnutrition [11]. Singh et al. revealed that the calorie and protein intakes of ICU patients were lower than the recommended level, and this is associated with a high mortality rate [12]. Many of the problems associated with PEM of ICU patients include the increase in hospital infections due to reduced immune function, delayed wound healing due to decreased tissue repair, delay in mechanical ventilation device isolation of patients due to changes in vital functions of the body and, depression and mental disorders [13]. One of the many factors identified in the etiology of malnutrition is the decreased food intake during hospitalization. Adequate daily intake is an essential factor in the treatment of malnutrition [14]; therefore, nutritional status has an impact on the ability to overcome critical conditions and clinical outcomes, especially in ICU patients. Inadequate food intake in these patients, in addition to nutritional deficiencies, can cause deterioration of health conditions and accelerate the onset of many disorders. The present study was conducted to determine the nutritional status of patients admitted to ICU.

\section{Materials and Methods}

The systematic review and meta-analysis were performed according to the meta-analysis of observational studies in epidemiology (MOOSE) guidelines [15].

\section{Search Strategy}

We used four databases: Medline (via PubMed), Embase, Web of Science, and Scopus in this study. The search was restricted to the years 2015 to 2019 because the nutritional status and prevalence of malnutrition in recent years was the focus of the present study. Keywords related to nutritional status in combination with words related to ICUs were used for search.

\section{Inclusion and Exclusion Criteria}

In the present study, we included studies that were published between $1^{\text {st }}$ January 2014 to $16^{\text {th }}$ August 2019, were cohort, case-control, or cross-sectional studies, involved ICU unit type, had patient's referral date after $31^{\text {st }}$ December 2013, and involved nutrition/malnutrition status. Also, old literature, pediatric, in which the patient's referral date was before $31^{\text {st }}$ December 2013 studies were excluded from the systematic review.

\section{Data Extraction}

After applying the inclusion and exclusion criteria for eligible studies, items such as first author name, sample size, number of malnutrition cases, method of obtained nutrition status, and findings were independently extracted by two reviewers after carefully reviewing the articles.

\section{Quality Assessment}

The quality of studies included in the meta-analysis was assessed using the Newcastle-Ottawa Scale (NOS) [16]. According to the NOS, studies scoring seven or more were regarded as having a low risk of bias; 4-6 a modest risk of bias; and studies $<3$ were considered to be at substantial risk of bias [17].

\section{Statistical Analysis}

The proportion of the number of malnutrition cases to the total number of patients was analyzed using the metafor package in R software version 3.6.1 (https://www.r-project.org/) [18]. To assess the homogeneity between the studies, the Cochran's heterogeneity (Q) and I2 statistics were used. Based on these statistics, the fixed effect and random-effect models were applied to obtain the pooled proportion of the number of malnutrition cases [19]. Also, to assess publication bias, Egger's regression test for asymmetry studies was used [20,21]. We used two strata (severe and mild-moderate) in the present study since all studies did not indicate all malnutrition status (severe, 
moderate, and mild). Therefore, the stratified analysis was used to identify the burden of overall malnutrition status. Also, subgroup analysis performed for the type of studies include cross-sectional, case-control, and cohort studies as well as developed and developing countries for the proportion of patients with malnutrition regardless of malnutrition status.

\section{Results}

\section{Study Selection}

After a search in databases, we detected 8024 records (PubMed: 1571, Embase: 3126, Web of Science: 460, Scopus: 2863, and other sources: 4). Of these studies, 3287 were duplicates, 2873 did not include nutritional status, malnutrition, as well as the type of ICU unit. Then, 1875 records were removed after apply- ing the filters (published during 2014-2019, the patient's referral date after $31^{\text {st }}$ December 2013, and cross-sectional/ cohort/ case-control studies). After the screening of titles, abstracts, and full-text screening, 23 records [22-44] were included for systematic review and meta-analysis (Figure-1).

\section{Characteristics of Studies}

From a total of 30942 subjects included in the 23 studies, 6845 subjects had malnutrition. The mean age of the subjects was 59.63 years. In all included studies, five studies were cross-sectional, two studies were case-control, and 16 studies were cohorts. Also, from these studies, only 13 studies indicated malnutrition status (the three malnutrition status in severe, moderate, and mild). Further details are shown in Table-1.

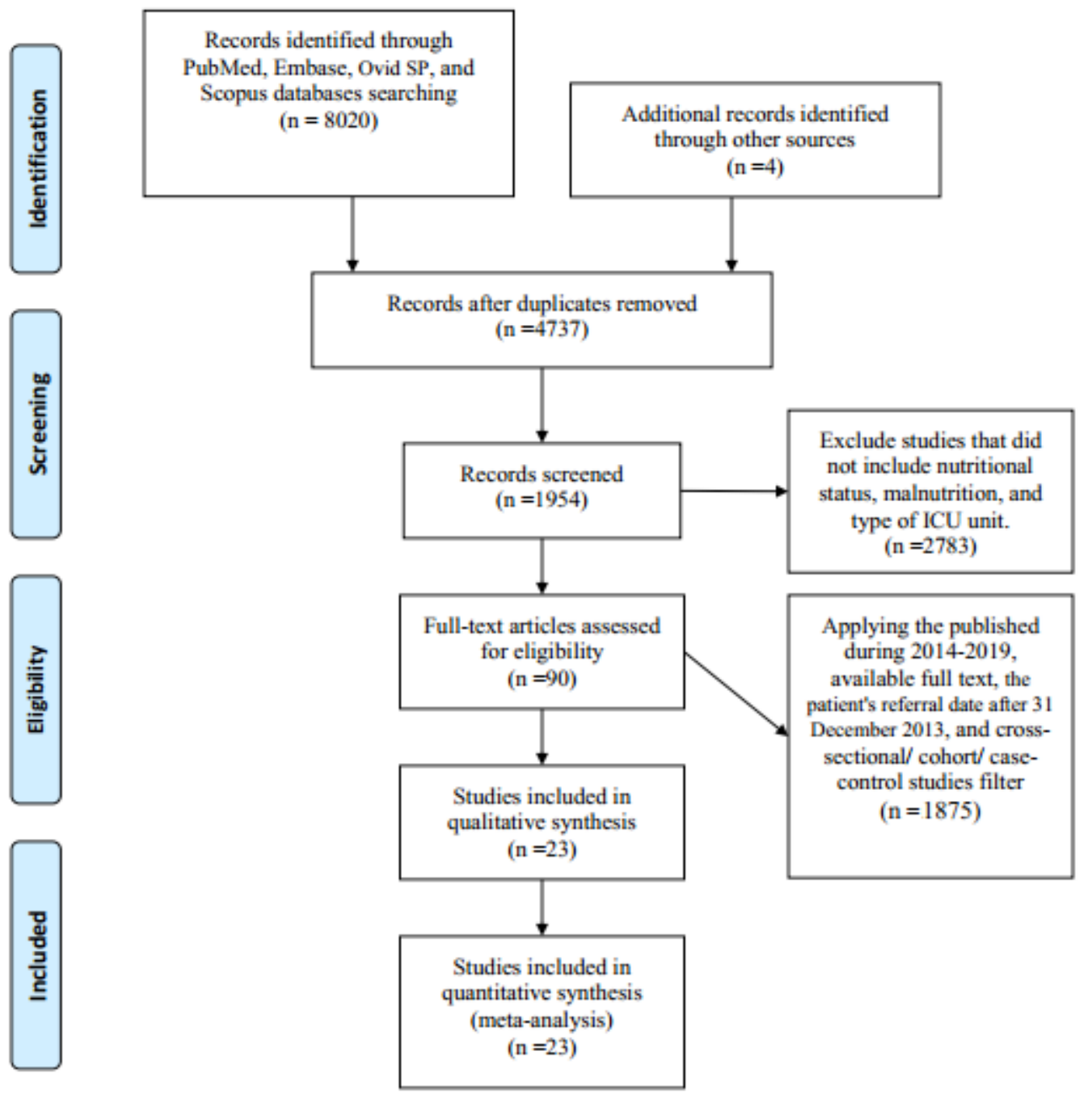

Figure 1. Flowchart of study 


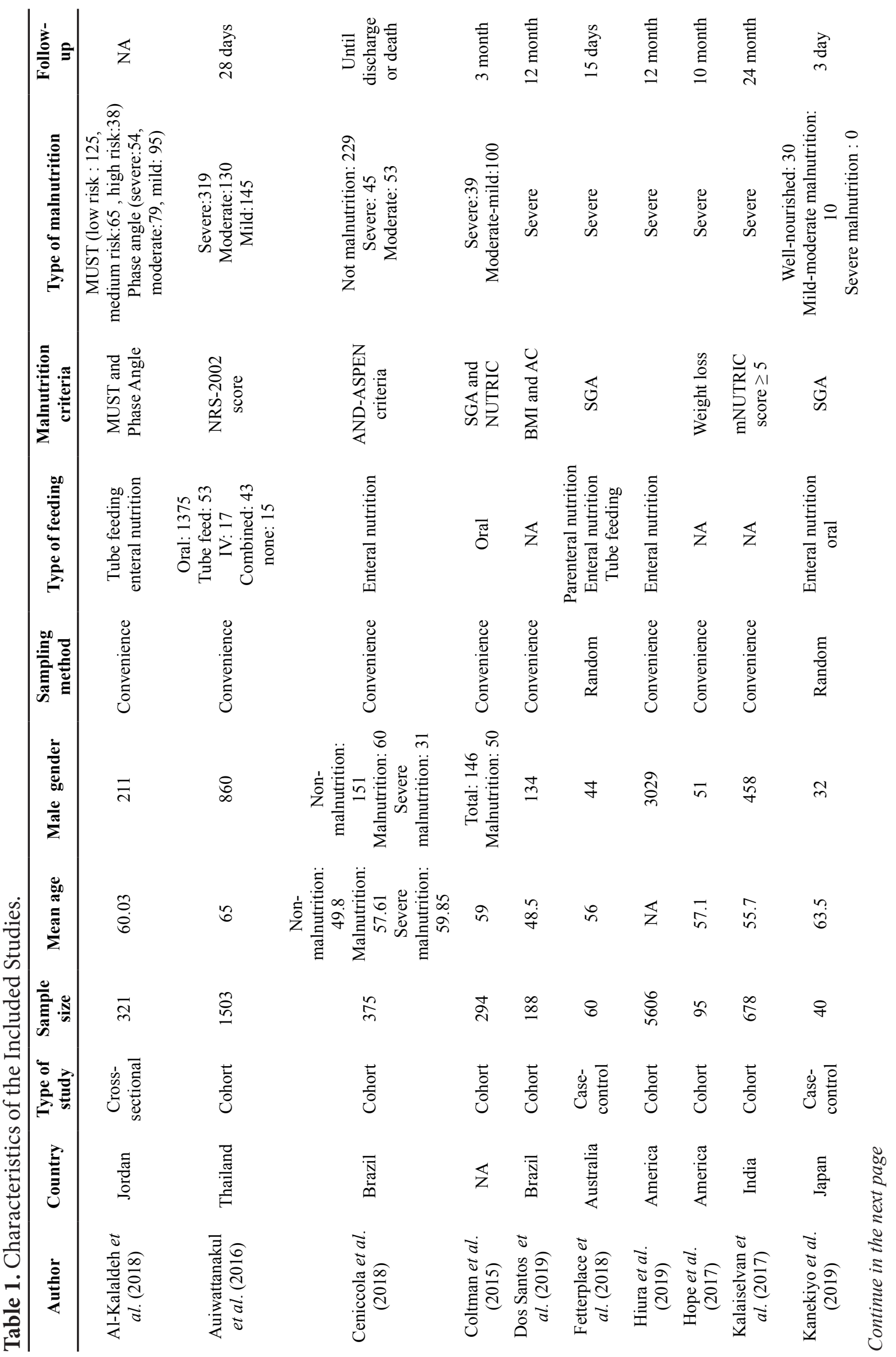




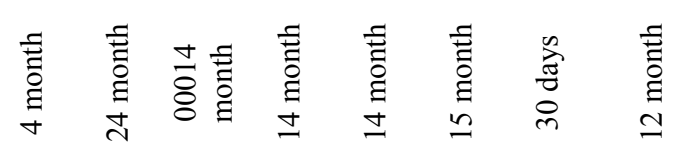

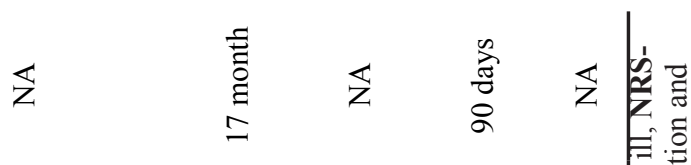

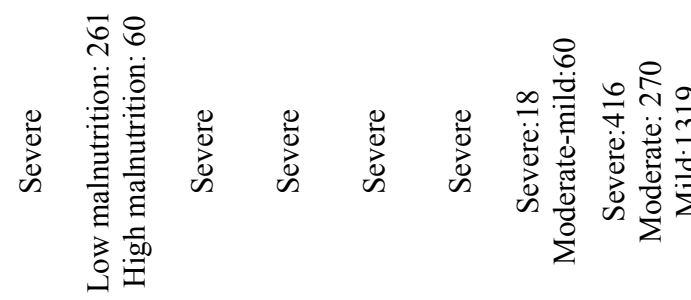

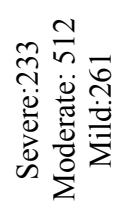

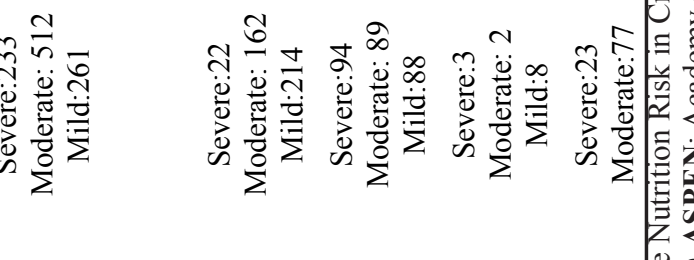

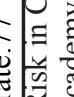

ڤิ่

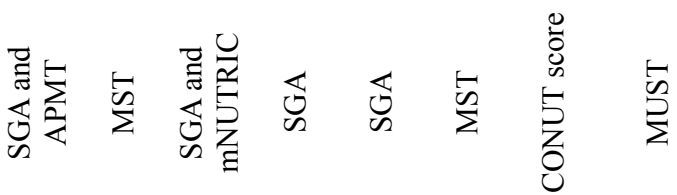

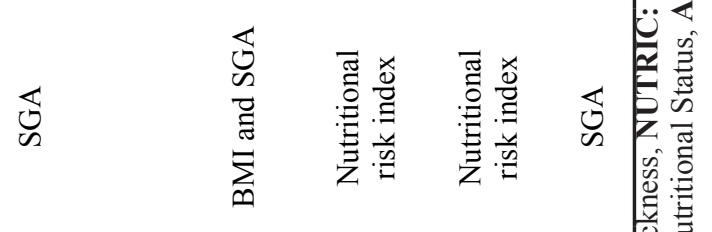

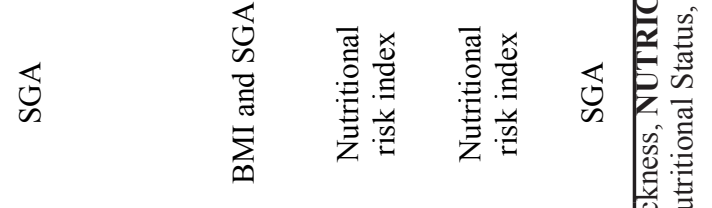

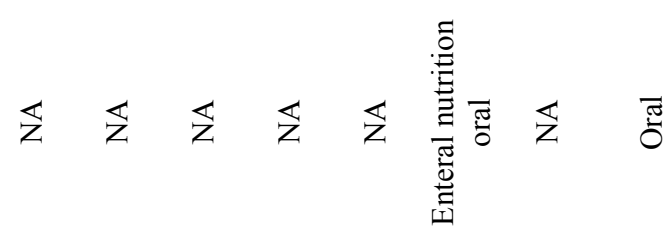

总:

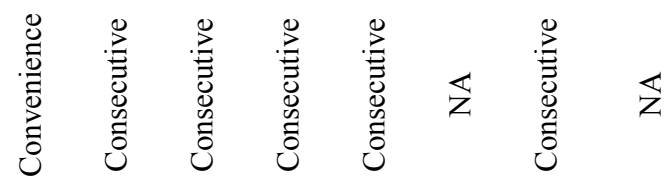

造

乙

o

芒

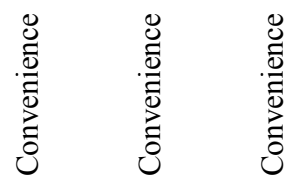

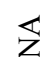

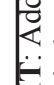

ก ๙

ฮิ

\& $\stackrel{\infty}{\infty}$ के $\mathbb{z}$

중

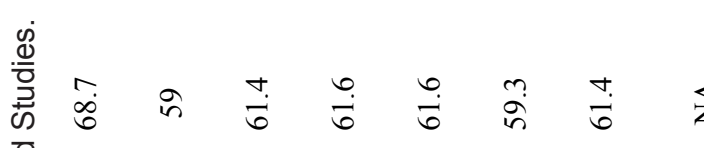

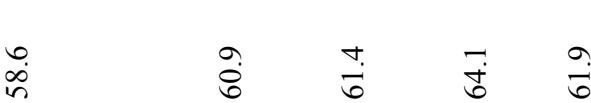

음

શ)

$\stackrel{ }{\check{2}}$

กิ

$\stackrel{\infty}{2} \stackrel{\infty}{\sim} \quad \infty$

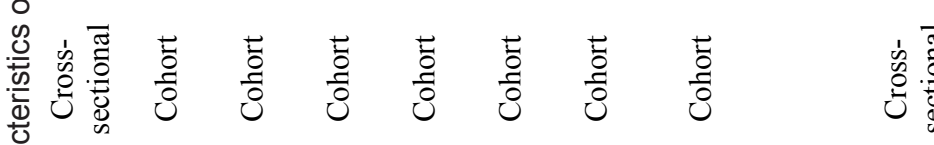

施

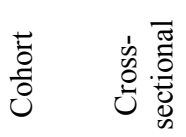

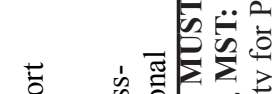

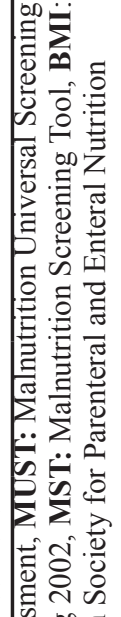

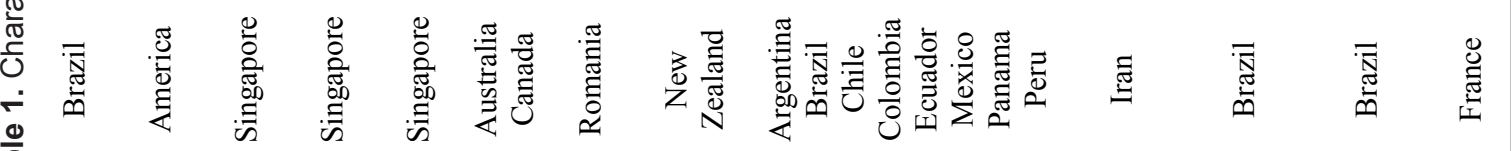
에

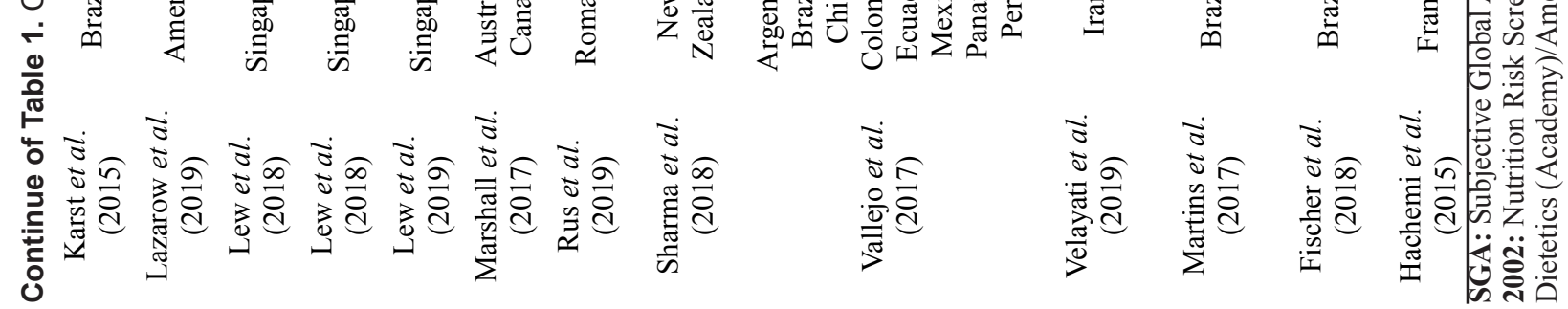




\section{Overall Publication Bias}

Based on the funnel plot, Egger's, and rank regression test, there was a significant publication bias between studies. The P-value of Egger's regression test was 0.004 . The funnel plot is presented in Figure-2.

\section{Stratified Malnutrition Status}

The present meta-analysis consists of three stratified malnutrition status, including severe, moderate, and mild. Therefore, since all the studies did not include all three status, we combined the moderate and mild conditions and compared them with the severe condition. The results of this section show that the proportion of people who are mild-moderate malnourished and severe malnutrition is 0.46 (with a $95 \%$ confidence interval [CI] $0.28-$ 0.64 ) and 0.20 (with a 95\% CI $0.14-0.27$ ), respectively. Since heterogeneity was higher than $=98 \%(\mathrm{P}<0.01)$, a random effect model was used to construct the combined confidence interval. The Forest plot for stratified malnutrition status is presented in Figure-3.

\section{Subgroup Analysis}

Subgroup analysis was performed for all included study types (cross-sectional, case-control, and cohort studies) and countries development (developed and developing).
Therefore, the proportion of people who are malnourished in cross-sectional/case-control/ cohort studies and developed/developing countries are 0.82 (95\% CI: $0.62-0.92) / 0.2$ (95\% CI: $0.13-0.30) / 0.43$ (95\% CI: $0.33-$ $0.54)$ and 0.37 (95\% CI: $0.28-0.46) / 0.64$ ( $95 \%$ CI: $0.48-0.78$ ), respectively. Finally, the pooled proportion in the two subgroups analysis was 0.51 (95\% CI: $0.39-0.62)$. Forest plot for subgroup analysis is presented in Figures-4 and 5.

\section{Evaluated Studies}

Based on the three categories of NOS, the total score for one study is 8 ; for two studies is 7 , for two studies is 6 , for five studies is 5 , for five studies is 4 , for six studies is 3 , and for two studies is 2 . Assessments of studies are shown in Table-2.

\section{Discussion}

These studies have shown that the nutritional status of patients in ICU is inappropriate with a high percentage of different degrees of malnutrition (the pooled proportion was 51\%). Also, severe malnutrition in this unit is $20 \%$, and for developing countries is $64 \%$. Malnutrition is a serious problem among many ICU patients [8]. Studies have shown that not pay-

\section{Funnel Plot Asymmetry}

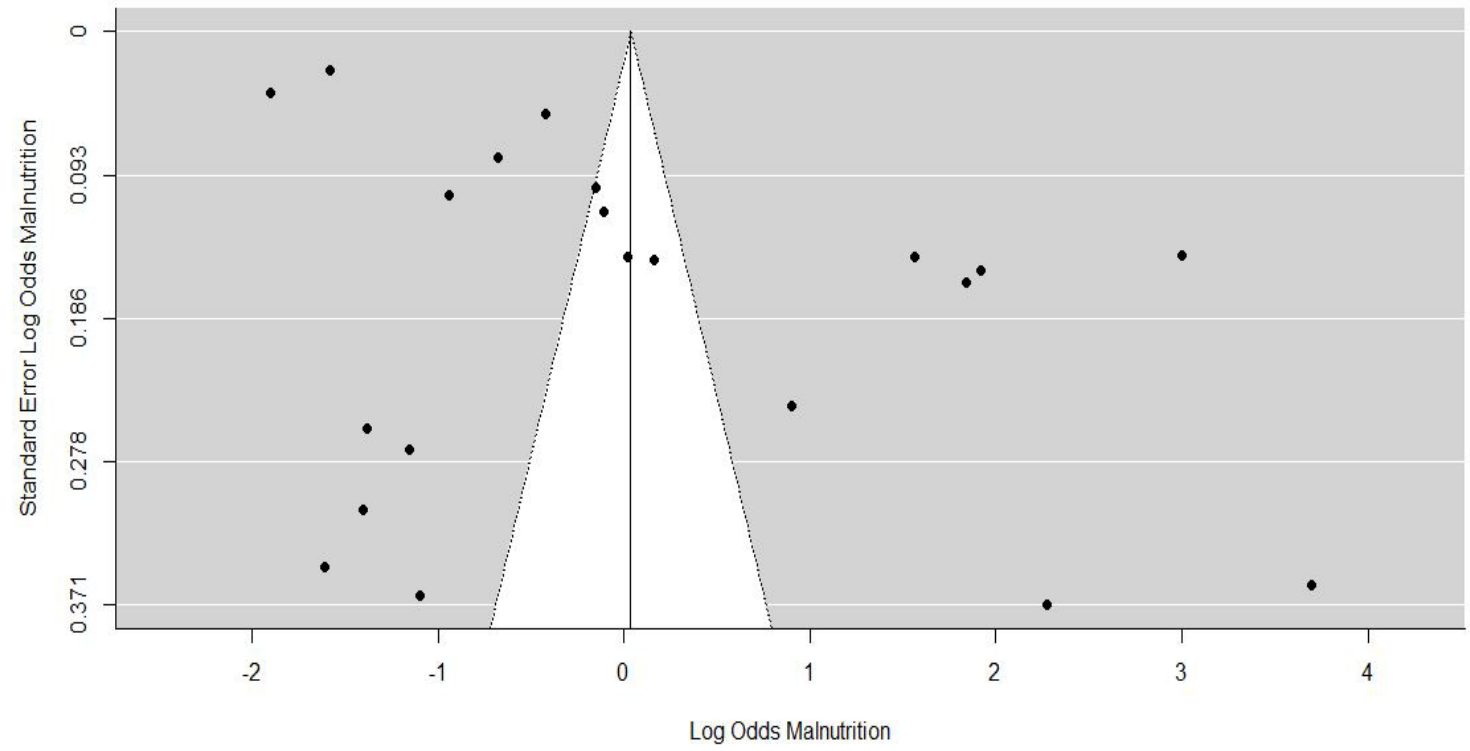

Figure 2. Funnel plot asymmetry for publication bias in 23 studies. 


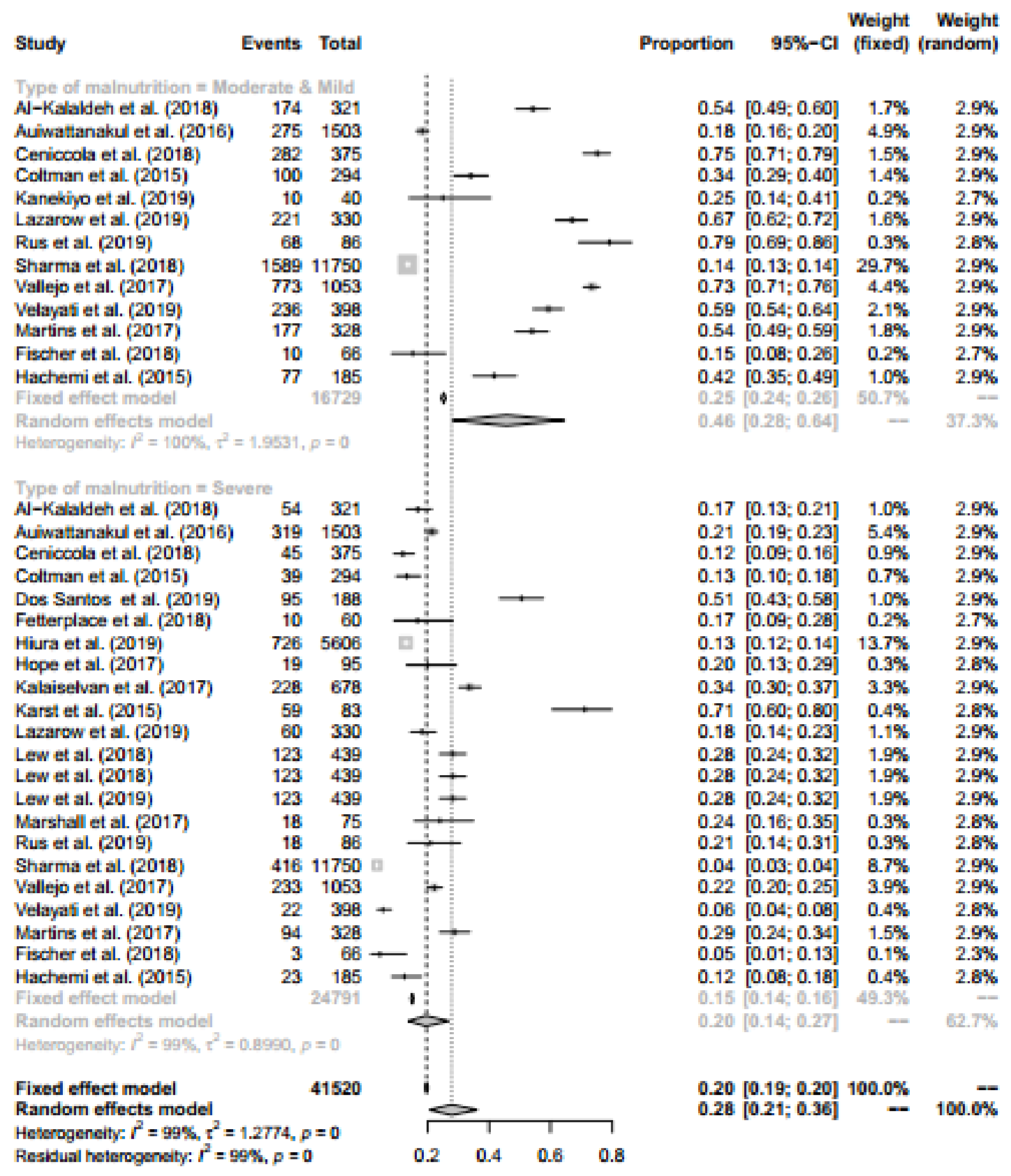

Figure 3. Forest plot for stratified malnutrition status.

ing attention to the nutritional needs of ICU patients can lead to deterioration of the disease, increased length of the disease, ventilator dependence, and high cost $[34,35,45,46]$. Studies also indicate that disruption in the provision of nutritional needs of ICU patients leads to a higher calorie deficit during critical periods of the disease. Some factors which can cause inadequate nutrition in patients include nutritional disruption for diagnostic procedures, nutrition discontinuation in managing the remaining gastric ulcer, lack of nutritional requirements, and delayed nutritional support $[2,9]$. In modern medicine, the concept of "nutrition therapy" is a substitute for supportive nutrition, which plays a vital role in the nursing care of ICU patients [3]. Relatively, specific measures that have to be taken include periodic visits by a nutritionist and implementation of nutritional guidelines for ICU patients. Studies have shown that nutritional counseling, along with diverse strategies of a nutritional support team at the hospital, especially ICU, has led to a reduction in the 


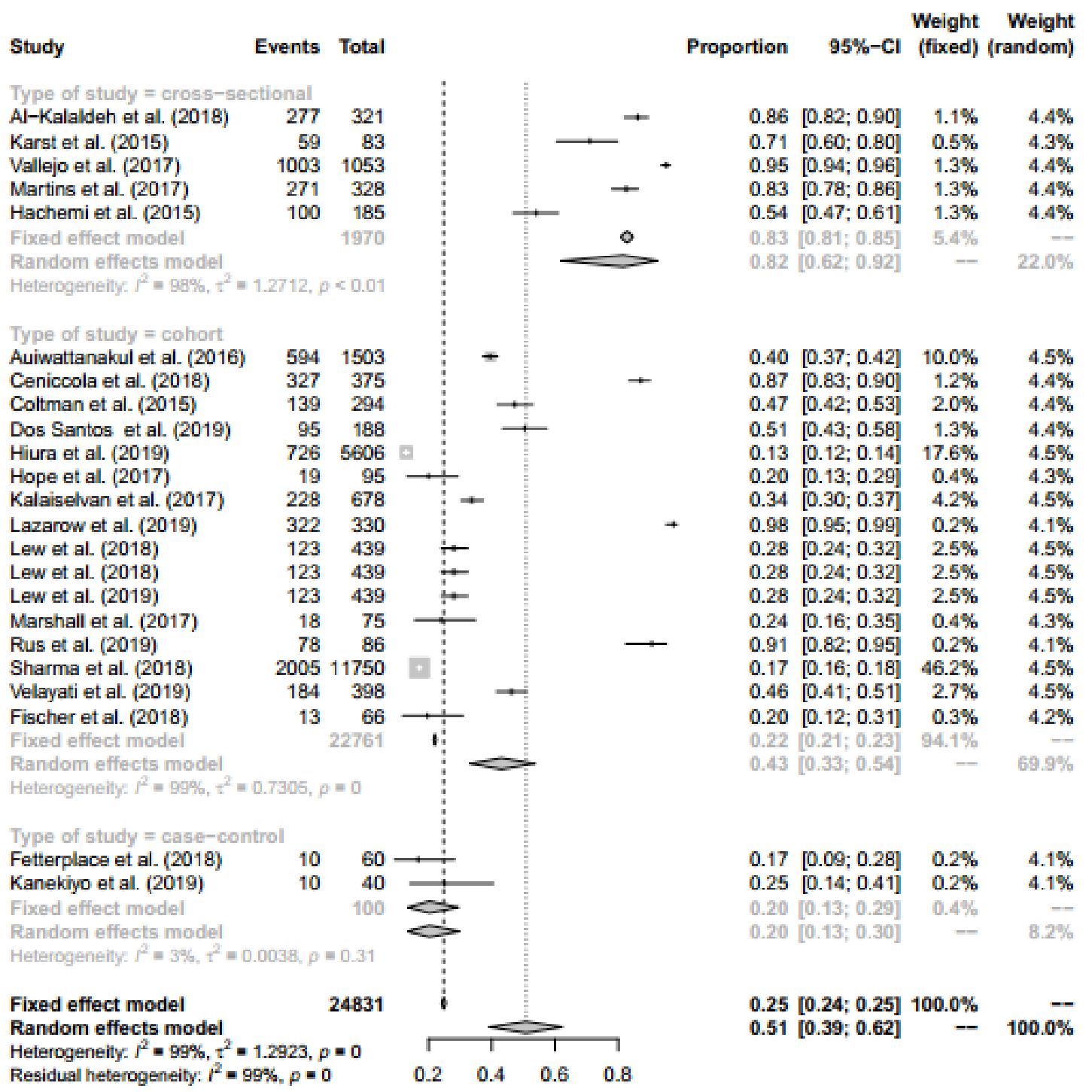

Figure 4. Forest plot for cross-sectional, case-control, and cohort studies subgroup analysis.

prevalence of malnutrition $[47,48]$. The presence of experts and nutritional support team can significantly improve the performance of ICU staff by providing adequate nutritional support [49]. In a study performed by Park et al., the presence of a nutritional support team had a positive and significant effect on the nutritional and clinical outcomes of ICU patients [48]. Evidence suggests that using these guidelines and nutritional protocols can help increase nutritional adequacy and prevent complications arising from inappropriate nutrition in ICU patients [50-52]. ICU patients are a heterogeneous group, and in order to meet their nutritional needs, a single approach cannot be used for each patient. The medical diagnosis of the different stages of the disease (early, post-recovery, stabilized, longterm residence) and any other complications should be taken into account simultaneously [2]. Nevertheless, the protocols provided by the European Society for Clinical Nutrition and Metabolism (ESPEN) present a set of nutrient recommendations in most clinical cases of the ICU [53]. Some of the advantages of using ESPEN protocols include timely and correct identification of high-risk patients, nutritional evaluation of ICU patients, determination of energy needs for each patient, and selecting appropriate methods to provide nutritional support based on the patients' clinical conditions [2]. 


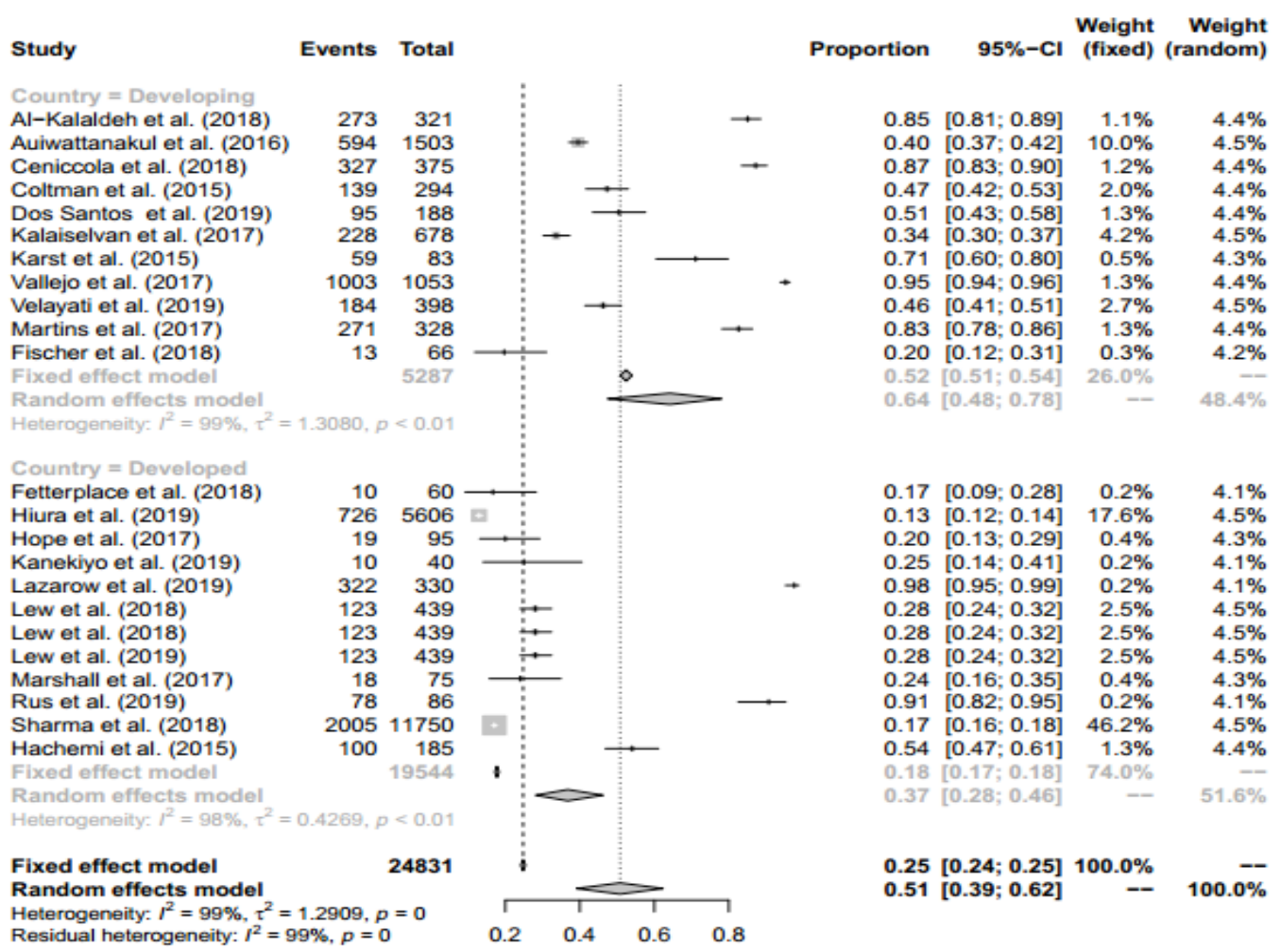

Figure 5. Forest plot for developed and developing countries subgroup analysis.

Table 2. Assessment of Study Quality Using the NOS

\begin{tabular}{|c|c|c|c|c|}
\hline Authors & Selection & Comparability & Exposure & Total \\
\hline Al-Kalaldeh et al. (2018) & 3 & 1 & 2 & 6 \\
\hline Auiwattanakul et al. (2016) & 3 & 1 & 1 & 5 \\
\hline Ceniccola et al. (2018) & 4 & 1 & 1 & 6 \\
\hline Coltman et al. (2015) & 4 & 1 & 3 & 8 \\
\hline Dos Santos et al. (2019) & 1 & 0 & 2 & 3 \\
\hline Fetterplace et al. (2018) & 2 & 1 & 2 & 5 \\
\hline Hiura et al. (2019) & 3 & 0 & 1 & 4 \\
\hline Hope et al. (2017) & 3 & 0 & 1 & 4 \\
\hline Kalaiselvan et al. (2017) & 1 & 0 & 1 & 2 \\
\hline Kanekiyo et al. (2019) & 2 & 1 & 1 & 4 \\
\hline Karst et al. (2015) & 2 & 1 & 2 & 5 \\
\hline Lazarow et al. (2019) & 2 & 0 & 1 & 3 \\
\hline Lew et al. (2018) & 2 & 0 & 1 & 3 \\
\hline Lew et al. (2018) & 2 & 0 & 1 & 3 \\
\hline Lew et al. (2019) & 2 & 0 & 1 & 3 \\
\hline Marshall et al. (2017) & 1 & 0 & 1 & 2 \\
\hline Rus et al. (2019) & 3 & 0 & 1 & 4 \\
\hline Sharma et al. (2018) & 3 & 2 & 2 & 7 \\
\hline Vallejo et al. (2017) & 3 & 2 & 2 & 7 \\
\hline Velayati et al. (2019) & 1 & 1 & 1 & 3 \\
\hline Martins et al. (2017) & 2 & 2 & 1 & 5 \\
\hline Fischer et al. (2018) & 3 & 0 & 2 & 5 \\
\hline Hachemi et al. (2015) & 1 & 2 & 1 & 4 \\
\hline
\end{tabular}




\section{Conclusion}

The results of this study revealed that the nutritional status of patients in the ICU is inappropriate, and most ICU patients are facing varying degrees of malnutrition. Malnutrition was associated with unfavorable clinical outcomes, such as increased length of stay in ICU, the duration of mechanical ventilation, and mortality rate. Therefore, it is necessary to accurately analyze the nutritional status of patients at the beginning and during their admission and to implement nutritional guidelines developed for the ICU by a professional nutritional support team, including nutritionists, physicians, and nurses.

\section{Conflict of Interest}

The authors declare no conflict of interest.

\section{References}

1. Huynh TN, Kleerup EC, Raj PP, Wenger NS. The opportunity cost of futile treatment in the intensive care unit. Crit Care Med. 2014;42(9):1977.

2. Singer P, Blaser AR, Berger MM, Alhazzani W, Calder PC, Casaer MP, et al. ESPEN guideline on clinical nutrition in the intensive care unit. Clin Nutr. 2019;38(1):4879.

3. Shabanpur M, Nachvak SM, Moradi S, Hedayati S, Hosseinikia M, Pasdar Y, et al. Nutritional Care in Iranian Intensive Care Units. Clin Nutr Res. 2018;7(2):136-45.

4. Weijs P, Mogensen K, Rawn J, Christopher K. Protein intake, nutritional status and outcomes in icu survivors: A single center cohort study. J Clin Med. 2019;8(1):43.

5. Fuhrmann K, Panamonta N, Roaten S. Malnutrition in the ICU: Current recommendations for the assessment of nutritional status and a review of the use of albumin as an indicator of malnutrition. The Southwest Respiratory and Critical Care Chronicles. 2013;1(4):8-14.

6. Webb A. Oxford textbook of critical care: Oxford University Press; 2016.

7. Berger MM, Pichard C. Best timing for energy provision during critical illness. Crit Care. 2012;16(2):215.

8. Shayesteh F, Poudineh S, Pouryazdanpanah-Kermani M, Sadat Ayoudi S, Norouzy A. Assessment of nutritional intake in intensive care unit patients of Ghaem hospital. Iran J Basic Med Sci. 2015;58(4):217-24.

9. Osooli F, Abbas S, Farsaei S, Adibi P. Identifying critically ill patients at risk of malnutrition and underfeeding: a prospective study at an academic hospital. Adv Pharm Bull. 2019; 9(2): 314-320.
10. Powers J, Samaan K. Malnutrition in the ICU patient population. Crit Care Nurs Clin North Am. 2014;26(2):227-42.

11. Verghese PP, Mathai AS, Abraham V, Kaur P. Assessment of malnutrition and enteral feeding practices in the critically ill: A single-centre observational study. Indian J Anaesth. 2018;62(1):29.

12. Singh N, Gupta D, Aggarwal AN, Agarwal R, Jindal SK. An assessment of nutritional support to critically ill patients and its correlation with outcomes in a respiratory intensive care unit. Respir Care. 2009;54(12):1688-96.

13. Ramprasad R, Kapoor MC. Nutrition in intensive care. J Anaesthesiol Clin Pharmacol. 2012;28(1):1.

14. Agarwal E, Ferguson M, Banks M, Bauer J, Capra S, Isenring E. Nutritional status and dietary intake of acute care patients: results from the Nutrition Care Day Survey 2010. Clin Nutr. 2012;31(1):41-7. 15. Stroup DF, Berlin JA, Morton SC, Olkin I, Williamson GD, Rennie D, et al. Meta-analysis of observational studies in epidemiology: a proposal for reporting. Meta-analysis Of Observational Studies in Epidemiology (MOOSE) group. Jama. 2000;283(15):2008-12.

16. The Newcastle-Ottawa Scale (NOS) for assessing the quality of nonrandomizedstudies in meta-analyses. http://www.medicine.mcgill.ca/rtamblyn/ Readings5CThe20Newcastle20-20Scale20for 20assessing20the20quality20of20nonrandom ised20studies $20 \mathrm{in} \% 20$ meta-analyses.pdf [ 17. Sabbagh HJ, Hassan MH, Innes NP, Elkodary HM, Little J, Mossey PA. Passive smoking in the etiology of nonsyndromic orofacial clefts: a systematic review and meta-analysis. PloS one. 
2015;10(3):e0116963.

18. Viechtbauer W. Conducting metaanalyses in $\mathrm{R}$ with the metafor package. Journal of Statistical Software. 2010;36(3):148.

19. Michael Borenstein LH, Hannah Rothstein. Meta-Analysis Fixed effect vs. random effects. 2007.

20. Egger M, Smith GD, Schneider $\mathrm{M}$, Minder C. Bias in meta-analysis detected by a simple, graphical test. BMJ. 1997;315(7109):629.

21. Begg CB, Mazumdar M. Operating Characteristics of a Rank Correlation Test for Publication Bias. Biometrics. 1994;50(4):1088-101.

22. Al-Kalaldeh M, Alghabeesh S, Suleiman K, Abu-Sharour L. Assessment of Nutritional Status of Critically Ill Patients Using the Malnutrition Universal Screening Tool and Phase Angle. Topics in Clin Nutr. 2018;33(2):134-43.

23. Auiwattanakul S, Chittawatanarat K, Chaiwat O, Morakul S, Kongsayreepong S, Ungpinitpong W, et al. Effects of nutrition factors on mortality and sepsis occurrence in a multicenter university-based surgical intensive care unit in Thailand (THAI-SICU study). Nutrition. 2019;58:94-9.

24. Ceniccola G, Holanda T, Pequeno R, Mendonça V, Oliveira A, Carvalho L, et al. Relevance of AND-ASPEN criteria of malnutrition to predict hospital mortality in critically ill patients: A prospective study. J Crit Care. 2018;44:398-403.

25. Coltman A, Peterson S, Roehl K, Roosevelt H, Sowa D. Use of 3 tools to assess nutrition risk in the intensive care unit. JPEN J Parenter Enteral Nutr. 2015;39(1):2833.

26. Santos HVDd, Araújo ISd. Impact of protein intake and nutritional status on the clinical outcome of critically ill patients. Rev Bras Ter Intensiva. 2019;31(2):210-6. 27. Fetterplace K, Deane AM, Tierney A, Beach LJ, Knight LD, Presneill J, et al. Targeted full energy and protein delivery in critically ill patients: a pilot randomized controlled trial (FEED trial). JPEN J Parenter Enteral Nutr. 2018;42(8):1252-62.

28. Hiura G, Lebwohl B, Seres DS. Malnutrition Diagnosis in Critically Ill Patients Using 2012 Academy of Nutrition and Dietetics/American Society for Parenteral and Enteral Nutrition Standardized Diagnostic Characteristics Is Associated With
Longer Hospital and Intensive Care Unit Length of Stay and Increased In-Hospital Mortality. JPEN J Parenter Enteral Nutr. 2020;44(2):256-264.

29. Hope AA, Hsieh S, Petti A, HurtadoSbordoni M, Verghese J, Gong MN.

Assessing the usefulness and validity of frailty markers in critically ill adults. Ann Am Thorac Soc. 2017;14(6):952-9.

30. Kalaiselvan M, Renuka M, Arunkumar A. Use of nutrition risk in critically ill (nutric) score to assess nutritional risk in mechanically ventilated patients: A prospective observational study. Indian J Crit Care Med. 2017;21(5):253.

31. Kanekiyo S, Takeda S, Iida M, Nishiyama M, Kitahara M, Shindo Y, et al. Efficacy of perioperative immunonutrition in esophageal cancer patients undergoing esophagectomy. Nutrition. 2019;59:96-102. 32. Karst FP, Vieira RM, Barbiero S. Relationship between adductor pollicis muscle thickness and subjective global assessment in a cardiac intensive care unit. Rev Bras Ter Intensiva. 2015;27(4):369-75. 33. Lazarow H, Nicolo M, Compher C, Kucharczuk CR, Stadtmauer EA, Landsburg DJ. Nutrition-Related Outcomes for Autologous Stem Cell Transplantation Patients. Clin Lymphoma Myeloma Leuk. 2019.

34. Lew CCH, Cheung KP, Chong MFF, Chua AP, Fraser RJ, Miller M. Combining 2 commonly adopted nutrition instruments in the critical care setting is superior to administering either one alone. JPEN J Parenter Enteral Nutr. 2018;42(5):872-6. 35. Lew C, Wong G, Cheung K, Chua A, Chong M, Miller M. Association between malnutrition and 28-day mortality and intensive care length-of-stay in the critically ill: a prospective cohort study. Nutrients. 2018;10(1):10.

36. Lew CCH, Wong GJY, Cheung KP, Fraser RJ, Chua AP, Chong MFF, et al. The association between nutritional adequacy and 28-day mortality in the critically ill is not modified by their baseline nutritional status and disease severity. Crit Care. 2019;23(1):222.

37. Marshall AP, Lemieux M, Dhaliwal R, Seyler H, MacEachern KN, Heyland DK. Novel, Family-Centered Intervention to Improve Nutrition in Patients Recovering From Critical Illness: A Feasibility Study. Nutr Clin Pract. 2017;32(3):392-9. 
38. Rus VA, Chitu M, Cernea S, Benedek I, Hodas R, Zavate R, et al. Altered nutritional status, inflammation and systemic vulnerability in patients with acute myocardial infarction undergoing percutaneous coronary revascularisation: A prospective study in a level 3 cardiac critical care unit. Rus VA, Chitu M, Cernea S, Benedek I, Hodas R, Zavate R, et al. Altered nutritional status, inflammation and systemic vulnerability in patients with acute myocardial infarction undergoing percutaneous coronary revascularisation: A prospective study in a level 3 cardiac critical care unit. Nutrition \& Dietetics. 2019. 39. Sharma Y, Miller M, Kaambwa B, Shahi R, Hakendorf P, Horwood C, et al. Factors influencing early and late readmissions in Australian hospitalised patients and investigating role of admission nutrition status as a predictor of hospital readmissions: a cohort study. BMJ open. 2018;8(6):e022246.

40. Vallejo KP, Martínez CM, Adames AAM, Fuchs-Tarlovsky V, Nogales GCC, Paz RER, et al. Current clinical nutrition practices in critically ill patients in Latin America: a multinational observational study. Crit Care. 2017;21(1):227.

41. Velayati A, Shariatpanahi MV, Shahbazi E, Shariatpanahi ZV. The association between preoperative nutritional status and postoperative delirium in individuals with coronary artery bypass graft surgery: A Prospective Cohort Study. Nutrition. 2019. 42. Velayati A, Vahdat Shariatpanahi M, Shahbazi E, Vahdat Shariatpanahi Z. Association between preoperative nutritional status and postoperative delirium in individuals with coronary artery bypass graft surgery: A prospective cohort study. Nutrition. 2019;66:227-32.

43. Martins RCFdC, Vital WC, Amaral JFd, Volp ACP. Perfil nutricional de pacientes internados em unidade de terapia intensiva. 2017.

44. de Queiroz Fischer M, Poll FA.

Relação entre o estado nutricional, nutrição precoce, hiperglicemia e desfecho clínico de pacientes internados em uma unidade de terapia intensiva. Revista de Epidemiologia e Controle de Infecção. 2019;9(1).
45. Lucas MCS, Fayh APT. Nutritional status, hyperglycemia, early nutrition, and mortality of patients hospitalized in an intensive care unit. Rev Bras Ter Intensiva. 2012;24(2):157-61.

46. Costa CA, Tonial CT, Garcia PCR. Association between nutritional status and outcomes in critically-ill pediatric patients-a systematic review. Jornal de pediatria. 2016;92(3):223-9.

47. Mo YH, Rhee J, Lee E-K. Effects of nutrition support team services on outcomes in ICU patients. Yakugaku Zasshi. 2011;131(12):1827-33.

48. Park YE, Park SJ, Park Y, Cheon JH, Kim TI, Kim WH. Impact and outcomes of nutritional support team intervention in patients with gastrointestinal disease in the intensive care unit. Medicine. 2017;96(49). 49. Terblanche E. The role of dietitians in critical care. J Intensive Care Soc. 2018:1751143718774715.

50. Sioson MS, Martindale R, Abayadeera A, Abouchaleh N, Aditianingsih D, Bhurayanontachai R, et al. Nutrition therapy for critically ill patients across the AsiaPacific and Middle East regions: A consensus statement. Clin Nutr ESPEN. 2018;24:15664.

51. Doig GS, Simpson F, Finfer S, Delaney A, Davies AR, Mitchell I, et al. Effect of evidence-based feeding guidelines on mortality of critically ill adults: a cluster randomized controlled trial. Jama. 2008;300(23):2731-41.

52. Barr J, Hecht M, Flavin KE, Khorana A, Gould MK. Outcomes in critically ill patients before and after the implementation of an evidence-based nutritional management protocol. Chest. 2004;125(4):1446-57. 53. Cederholm T, Barazzoni R, Austin P, Ballmer P, Biolo G, Bischoff SC, et al. ESPEN guidelines on definitions and terminology of clinical nutrition. Clin Nutr. 2017;36(1):49-64.

54. 